\title{
Temporal Variation in the Viability of Spermatozoa in the Spermathecae of Queen Honey Bees (Apis mellifera L.)
}

\author{
Yasin Kahya $^{1, a, *}$, H. Vasfi Gençer ${ }^{1, b}$ \\ ${ }^{I}$ Department of Animal Science, Faculty of Agriculture, Ankara University, 06110 Ankara, Turkey \\ *Corresponding author

A R T I C L E I N F O A B S T R A C T \\ Research Article \\ The storage of spermatozoa and keeping alive for years in the spermatheca by the honey bee queen \\ is a phenomenon allowing her to fertilize eggs throughout her life. In this study, the queens that \\ were 2-week, 1-year, and 2-year-old were analyzed to determine the viability of spermatozoa in \\ their spermathecae. The sister queens reared by the grafting method were instrumentally \\ Received : 27/11/2021 \\ Accepted : 03/02/2022 \\ inseminated with $8 \mu \mathrm{l}$ fresh semen when they became 6 days old. One week after instrumental \\ insemination, one batch of queens (2-week-old) was dissected for spermatozoa viability test. \\ Another set of queens was introduced into production colonies in Langstroth hives after the onset \\ of oviposition in the mating nuclei. The queens were maintained in production colonies for one year \\ and two years until the dissection process for spermatozoa viability test. The viability of \\ spermatozoa was measured by the dual staining method. We determined that the mean viability of \\ spermatozoa in 2-week, 1-year and 2-year-old queens were $97.3 \%, 91.1 \%$ and $88.1 \%$, respectively. \\ The viability of spermatozoa in queens decreased with age, and the differences between the viability \\ means were significant. However, we did not detect a steep decline in the viability of spermatozoa \\ in queens ( $6 \%$ in one year and $9 \%$ in two years) in a wide range of timescale in contrast to previous \\ reports. Furthermore, we found high viability of spermatozoa in the spermathecae of queens at the \\ start of their lives and one- and two-years of age.
}

\section{Introduction}

The main functions of spermatheca are to receive, protect and release spermatozoa to fertilize eggs in a longterm period. In several species, including insects and birds, spermatozoa are stored alive within one or a few spermathecae for weeks, months or years after matings (Pascini and Martins, 2017). The honey bee (Apis mellifera L.) queen is a model organism for studies on long-term spermatozoa storage. However, the studies are limited on the temporal variation in the viability of spermatozoa in the spermathecae of queens.

The queen is the only reproductive female responsible for egg laying in the honey bee colony. The queen starts her reproductive life by mating with several drones at about one week old after emergence. The queen mates with 7-17 drones during one or a few nuptial flights (Woyke, 1962; Winston, 1987; Kahya et al., 2008). The queen returns from mating to her hive with around 90-100 million spermatozoa in her lateral oviducts. After migration from lateral oviducts within 24 hours, the spermatheca contains about 4-5 million spermatozoa. The queen uses stock spermatozoa to fertilize the eggs during laying throughout her life.

The viability of spermatozoa in spermatheca is under the pressure of biotic and abiotic factors. The queen has to keep spermatozoa alive in the spermatheca for years under these factors. Keeping spermatozoa alive throughout her entire life is crucial for herself and her colony. The queen can manipulate the energy metabolism of spermatozoa to maximize competitiveness during spermatozoa migration. The queen also can minimize the damage of spermatozoa during long-term storage in the spermatheca. The queen maintains the viability of spermatozoa in the spermatheca via regulating spermathecal content. The proteins and enzymes (Weirich et al., 2002; Collins et al., 2004; Klenk et al., 2004; Al-Lawati et al., 2009; McAfee et al., 2021a; McAfee et al., 2021b;) and some metabolites such as lipids and lipid-like molecules (Liu et al., 2020) in the spermathecal fluid play essential role to conserve 
spermatozoa in the spermatheca. The concentration of $\mathrm{Na}^{+}$ and $\mathrm{K}^{+}$ions (Verma, 1978, 1973) and $\mathrm{pH}$ (Klenk et al., 2004) of the spermathecal fluid are also crucial measures for spermatozoa viability in the spermatheca.

Plentiful studies were carried out to understand the processes underlying mechanisms of spermatozoa storage in the spermathecae of queens. Interestingly, however, there are limited studies on the age-dependent variation in the viability of spermatozoa in the spermatheca. This study aims to determine how the viability of spermatozoa in the spermathecae of queens varies over two years. Therefore, we tested the viability of spermatozoa in instrumentally inseminated queens at different ages.

\section{Material and Methods}

The research was carried out at Ankara University, Turkey $\left(39^{\circ} 57^{\prime} 47.3^{\prime \prime} \mathrm{N}, 32^{\circ} 52^{\prime} 00.1^{\prime \prime E}\right)$ in the summer seasons of 2019 and 2021. The sister queens from one Caucasian (A. m. caucasica) colony were reared with standard grafting method (Laidlaw and Page, 1997). The queen cells were introduced into the Kirchain mating boxes one day before expected adult emergence. The attempts of natural mating flights of virgin queens were prevented by keeping queen excluder at the entrance of mating box. The queen excluder was not removed until each queen started to lay eggs. The virgin queens were inseminated with $8 \mu \mathrm{l}$ fresh semen collected from free-flying drones in our research apiary when they were 6 days old. Each queen was given to her mating box after instrumental insemination. One day after insemination, the queens were exposed to $\mathrm{CO}_{2}$ treatment for five minutes to stimulate ovarian development. One week after instrumental insemination, the queens were checked to determine the onset of oviposition in the mating boxes. Then, one group of queens (about 2 weeks old) was dissected for the spermatozoa viability test. Another set of laying queens was introduced into production colonies in Langstroth hives. The queens were maintained in production colonies until dissections for spermatozoa viability test at one year and two years. Standard beekeeping procedures were applied to all experimental colonies throughout the experiment. The queens were collected randomly from their hives when they reached 1-year and 2-year-old. The queens taken from their hives were kept 1-2 days in small wooden shipping cages with 5-6 attendant workers until dissection procedures in the laboratory.

The dual staining method was used for the spermatozoa viability test. First, each queen was dissected under a macroscope (Leica, Z16 Apo), and the spermatheca was taken out by cutting an opening on the dorsal side of the abdomen. Then, the surface of spermatheca was washed in $0.9 \% \mathrm{NaCl}$ solution after removing the tracheal net covering. The semen in the spermatheca was dispersed in
$125 \mu \mathrm{l}$ modified Kiev solution - MKS (Moritz, 1984) after puncturing and compressing it gently by fine forceps. The viability of spermatozoa was determined with the spermatozoa viability kit (L-7011, Molecular Probes) containing SYBR-14 and Propidium Iodide (PI) fluorescent dyes. After adding $0.6 \mu \mathrm{l}$ of each fluorescent dye, MKS-semen mixture in the microcentrifuge tube $(0.6 \mathrm{ml})$ were incubated at $36^{\circ} \mathrm{C}$ for 10 minutes in a water bath. Then, one drop aliquot from the stained MKSsemen mixture was placed on a glass slide. The slide was covered with a coverslip. The live (green) and dead (red) spermatozoa were counted simultaneously using a microscope with fluorescent attachment (Leica DM3000) and filters (I3 and N21) under 400x magnification. The viability of spermatozoa (\%) was calculated as the percentage of live spermatozoa number in the total (dead and live) spermatozoa counted. At least 400 spermatozoa were counted in each spermatheca (Gençer et al., 2014).

All statistical analyses and graphical representations were performed using Rstudio (Version 1.3.1073), and its libraries (rstatix, dplyr, tidyverse, ggpubr). After testing for normality and homogeneity by Shapiro-Wilk's test and Levene's test, the data were analyzed with ANOVA followed by Tukey test for multiple comparisons of queen age groups.

\section{Results and Discussion}

In total, 42 queens were used in the spermatozoa viability test. Seventeen of 42 queens were used when they were 2-week-old for the viability test. Nineteen and 6 of the remaining queens were dissected at one year (1year-old) and two years (2-year-old), respectively.

The viability of spermatozoa ranged from $82.1 \%$ to $99.5 \%$. The mean viability of spermatozoa in 2 -week, 1 year and 2-year-old queens were $97.3 \%, 91.1 \%$ and $88.1 \%$, respectively (Table 1 ). The differences in the viability of spermatozoa were found statistically significant between queen ages groups $(\mathrm{P}<0.0001$, Figure $1)$. The mean viability of spermatozoa of queens from 2 week-old $(97.3 \%)$ was significantly higher than 1 -year old $(91.1 \%, \mathrm{P}<0.0001)$ and 2 -year-old queens $(88.1 \%$, $\mathrm{P}<0.0001)$. The difference in the viability of spermatozoa between 1-year and 2-year-old queens was also statistically significant $(\mathrm{P}<0.05)$.

The results showed that the viability of spermatozoa in the spermatheca decreased gradually over two-year period. The viability of spermatozoa decreased from $97.3 \%$ to $91.1 \%$ in the first year, and the viability loss was $6.2 \%$. The viability loss was $3.0 \%$ in the second year, decreasing from $91.1 \%$ to $88.1 \%$. We did not determine any dramatic decrease in the viability of spermatozoa within two years.

Table 1. The viability of spermatozoa (\%) values determined in the spermathecae of two week, 1-year and 2-year-old queens

\begin{tabular}{l|cccc}
\hline \multicolumn{1}{c|}{ Queen Ages } & $\mathrm{n}$ & Mean \pm SD* & Minimum & Maximum \\
\hline Two-week & 17 & $97.3 \pm 0.02 \mathrm{a}$ & 93.8 & 99.5 \\
1-year & 19 & $91.1 \pm 0.03 \mathrm{~b}$ & 86.6 & 95.7 \\
2-year & 6 & $88.1 \pm 0.04 \mathrm{c}$ & 82.1 & 93.9 \\
\hline
\end{tabular}

*Different small letters denote significant differences between the viability of spermatozoa means. 


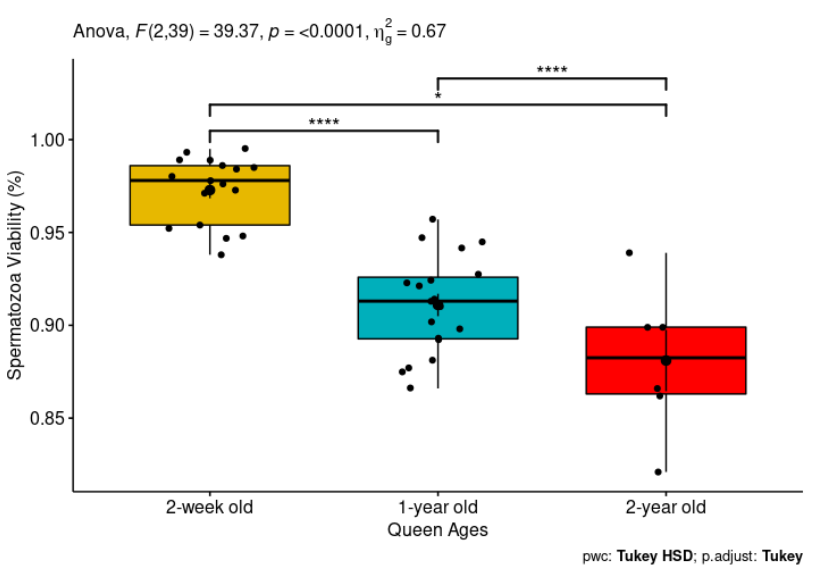

Figure 1 . The viability of spermatozoa (\%) variation in the spermathecae of queens at different ages. Significant differences in mean values are represented with one $\left(^{*}\right.$, $\mathrm{P}<0.05)$ or four asterisks $(* * * *, \mathrm{P}<0.0001)$.

The viability loss from the onset of oviposition to 2 years of age was only $9.2 \%$, decreasing from 97.3 to $88.1 \%$. After introducing the queens into the experimental colonies, we did not observe premature queen replacement attributable to the lower number or viability of spermatozoa in the spermatheca. Therefore, it can not be concluded that only surviving queens having higher viability of spermatozoa were tested.

Several studies were conducted on the viability of spermatozoa in the spermatheca. But, a few of these studies were on the temporal variation in the viability of spermatozoa in the spermatheca (Gençer and Kahya, 2011; Tarpy et al., 2012; Pettis et al., 2016; Chaimanee et al., 2019). At the beginning of the life, just after migration of spermatozoa, nearly all spermatozoa in the spermatheca is expected to be live, as only the live spermatozoa can migrate from lateral oviducts to the spermatheca (Gençer and Kahya, 2011). However, some authors reported a wide range of values in the viability of spermatozoa at the early life of the queens ranging from $42 \%$ (Chaimanee and Pettis, 2019) to 98\% (Gençer et al., 2014). The reason for the lower viability reports for the queens at the beginning of their lives may be some potential pitfalls in estimating the viability of spermatozoa (Holman, 2009).

Tarpy and Olivarez (2014) found that the viability of spermatozoa decreased steadily from $90.3 \%$ to $81.3 \%$ in a short time (9\% in 5 months). Lodesani et al. (2004) found that the viability of spermatozoa was $79.5 \%, 78.3 \%$ and $66.5 \%$ in 2-month, 12-month and 24-month-old queens, respectively. We, here, determined the higher viability of spermatozoa in queens compared to the findings of Lodesani et al. (2004) and of Tarpy and Olivarez (2014). Even the viability of spermatozoa in 2-year-old queens in our study was higher than the viability values previously reported for younger queens.

We found the highest viability loss $(6 \%)$ in one-year old queens. The viability loss in 2-year-old queens $(3 \%)$ was not higher than one-year old queens. We suggested that the stress in the spermatheca during the first year might be more influential on the viability of spermatozoa than during the second year. The increase in the proportion of dead spermatozoa in the spermatheca is a function of using only live spermatozoa to fertilize the eggs. Our results revealed that a limited number of additional spermatozoa death occurs in the spermatheca in the second year (3\%).

In beekeeping practices, the replacement of the queen is suggested for every two-year due to the decrease in the number of spermatozoa in the spermatheca. Our results demonstrated that the viability of spermatozoa in the spermatheca should not be the reason for the replacement of older queens.

\section{References}

Al-Lawati H, Kamp G, Bienefeld K. 2009. Characteristics of the spermathecal contents of old and young honeybee queens. Journal of Insect Physiology, 55:117-122. doi: 10.1016/j.jinsphys.2008.10.01

Chaimanee V, Pettis JS. 2019. Gene expression, sperm viability, and queen (Apis mellifera) loss following pesticide exposure under laboratory and field conditions. Apidologie, 50:304316. doi: 10.1007/s13592-019-00645-4

Collins AM, Williams V, Evans JD. 2004. Sperm storage and antioxidative enzyme expression in the honey bee, Apis mellifera. Insect Molecular Biology, 13:141-146. doi: 10.1111/j.0962-1075.2004.00469.x

Gençer HV, Kahya Y. 2011. The viability of sperm in lateral oviducts and spermathecae of instrumentally inseminated and naturally mated honey bee (Apis mellifera $\mathrm{L}$.) queens. Journal of Apicultural Research, 50:190-194. doi: 10.3896/IBRA.1.50.3.02

Gençer HV, Kahya Y, Woyke J. 2014. Why the viability of spermatozoa diminishes in the honeybee (Apis mellifera) within short time during natural mating and preparation for instrumental insemination. Apidologie, 45:757-770. doi: 10.1007/s13592-014-0295-0

Holman L. 2009. Sperm viability staining in ecology and evolution: potential pitfalls. Behavioral Ecology and Sociobiology, 63:1679-1688. doi: 10.1007/s00265-009-0816-4

Kahya Y, Gençer HV, Woyke J. 2008. Weight at emergence of honey bee (Apis mellifera caucasica) queens and its effect on live weights at the pre and post mating periods. Journal of Apicultural Research, 47:118-125. doi: 10.1080/00218839. 2008.11101437

Klenk M, Koeniger G, Koeniger N, Fasold H. 2004. Proteins in spermathecal gland secretion and spermathecal fluid and the properties of a $29 \mathrm{kDa}$ protein in queens of Apis mellifera. Apidologie, 35:371-381. doi: 10.1051/apido:2004029

Laidlaw HH, Page RE. 1997. Queen rearing and bee breeding. Wiswcas Press, Cheshire, Connecticut, USA.:224

Liu Z, Liu F, Li G, Chi X, Wang Y, Wang H, Ma L, Han K, Zhao G, Guo X, Xu B. 2020. Metabolite support of long-term storage of sperm in the spermatheca of honeybee (Apis mellifera) queens. Frontiers in Physiology, 11. doi: 10.3389/fphys.2020.574856

Lodesani M, Balduzzi D, Galli A. 2004. A study on spermatozoa viability over time in honey bee (Apis mellifera ligustica) queen spermathecae. Journal of Apicultural Research, 43:2728. doi: $10.1080 / 00218839.2004 .11101105$

McAfee A, Chapman A, Pettis JS, Foster LJ, Tarpy DR. 2021a. Trade-offs between sperm viability and immune protein expression in honey bee queens (Apis mellifera). Communications Biology, 4:1-11. doi: 10.1038/s42003-02001586-w

McAfee A, Tarpy DR, Foster LJ. 2021b. Queen honey bees exhibit variable resilience to temperature stress. PLOS ONE, 16:e0255381. doi: 10.1371/journal.pone.0255381

Moritz RFA. 1984. The effect of different diluents on insemination success in the honeybee using mixed semen. Journal of Apicultural Research, 23:164-167. doi: 10.1080/00218839.1984.11100626 
Pascini TV, Martins GF. 2017. The insect spermatheca: an overview. Zoology, 121:56-71. doi: 10.1016/j.zool .2016.12.001

Pettis JS, Rice N, Joselow K, vanEngelsdorp D, Chaimanee V. 2016. Colony failure linked to low sperm viability in honey bee (Apis mellifera) queens and an exploration of potential causative factors. PLOS ONE, 11: e0147220. doi: 10.1371/journal.pone.0147220

Tarpy DR, Keller JJ, Caren JR, Delaney DA. 2012. Assessing the mating "health" of commercial honey bee queens. Journal of Economic Entomology, 105:20-25. doi: 10.1603/ec11276

Tarpy DR, Olivarez R. 2014. Measuring sperm viability over time in honey bee queens to determine patterns in stored-sperm and queen longevity. Journal of Apicultural Research, 53:493-495. doi: 10.3896/IBRA.1.53.4.02
Verma LR. 1973. An ionic basis for a possible mechanism of sperm survival in the spermatheca of the queen honey bee (Apis mellifera L.). Comparative Biochemistry and Physiology Part A: Physiology, 44:1325-1331. doi: 10.1016/0300-9629(73)90272-7

Verma LR. 1978. Biology of honeybee (Apis mellifera L.) spermatozoa .1. Effect of different diluents on motility and survival. Apidologie, 9:167-173. doi: 10.1051/apido: 19780301

Weirich GF, Collins AM, Williams VP. 2002. Antioxidant enzymes in the honey bee, Apis mellifera. Apidologie, 33:314. doi: 10.1051/apido:2001001

Winston ML. 1987. The Biology of The Honey Bee. Cambridge, Mass: Harvard University Press.

Woyke J. 1962. Natural and artificial insemination of queen honeybees. Bee World, 43:21-25. doi: 10.1080/0005772X. 1962.11096922 